\title{
Patterns of Chemical Pesticide Use and Determinants of the Use of Personal Protective Equipment to Minimize Chemical Exposure in Vegetable Farming, Maldives
}

\author{
Mariyam Shajua ${ }^{1}$, Wongsa Laohasiriwong ${ }^{2}$ \\ ${ }^{1}$ Master of Rural Development Management, KhonKaen University, Thailand, \\ ${ }^{2}$ Associate Professor, Faculty of Public Health, KhonKaen University, Thailand
}

\begin{abstract}
Background: The overuse of chemical pesticides without proper Personal Protective Equipment (PPE) use has put vegetable farmers at risk and has been an extreme concern over the past decades in the Maldives. Therefore, this study aimed to describe the patterns of chemical pesticide use and determinants of PPE use to diminish chemical exposure.
\end{abstract}

Method: This cross-sectional study applied a two-stage random sampling method to select the study subjects to respond a structured questionnaire. The multiple logistic regression was applied to determine the association.

Results: Of 306 respondents, $90 \%$ used chemical pesticides while only $23 \%$ used PEE. Themultivariable analysis indicated the use of PPE was significantly associated with education attainment (adj.OR=3.17, 95\% CI $=1.80-5.57$, $\mathrm{p}$-value $=<0.001$ ), amount of chemical pesticide used per month (adj.OR=2.20, 95\% $\mathrm{CI}=1.37-4.43$, $\mathrm{p}$-value $=0.002$ ), main sources of pesticide information (adj.OR=2.31, 95\% CI=1.334.01, $\mathrm{p}$-value $=0.003$ ), hired someone to spray chemical pesticides (adj. OR=2.46, 95\% CI=1.13-4.31, $\mathrm{p}$-value $=0.02)$, and ever participated in any farming-related trainings $(\operatorname{adj} . \mathrm{OR}=2.97,95 \% \mathrm{CI}=1.63-5.49$, $\mathrm{p}$-value $=<0.001)$.

Conclusions: Almost all of the farmers used chemical pesticides and less than a quarter used full PPE. Educational attainment, quantity of pesticides used, sources of pesticide information and other farming practices have a strong relationship with PPE use.

Keywords: Chemical Pesticides, Personal Protective Equipment, Vegetable Farming.

\section{Introduction}

A pesticide isdefined as any chemical substance intended for eliminating, repelling or controlling certain forms of plant or animal life that are considered to be pests, produced and used worldwide especially in developing countries ${ }^{1}$. Nowadays, chemical pesticides

\section{Corresponding Author:}

Wongsa Laohasiriwong

Address: Associate Professor, Dean, Faculty of Public

Health, KhonKaen University, Thailand

e-mail: wongsa@kku.ac.th play an essential role in modern agriculture as a commodity to prevent crop loss from pests, raising the yield to sustainably feed the rapid growth of the world population which has doubled to around 7 billion since the $1970 \mathrm{~s}^{2}$. Chemical pesticides used in agriculture are rapidly increasing in developing countries, particularly in Southeast Asia, as most member countries 'economies depend heavily on agriculture. The annual rise in pesticide imports for Cambodia is estimated at $61 \%$, for Laos at $55 \%$, and Vietnam at $10 \%{ }^{3}$.

With the overuse of chemical pesticides, pesticide pollution has become a significant global issue ${ }^{4}$. It is generally well known that applicators and their families receive the greatest pesticide hazards, particularly 
in developing countries where a large number of the population contributes to agriculture, where the pesticides are sprayed manually with simple equipment, and applicators have a low level of awareness about pesticide impacts and safety.According to a report conducted by PAN International, 41 million among 1.3 billion farmers were affected by pesticide poisoning at $32 \%$ annually ${ }^{5}$. While all counties have their registry of pesticides, protocols, and guidelines for safe use of pesticides, some countries still lack the required tools such as accessibility to PPEs, trainings in pesticide protection management which slows down the full implementation of pesticide adverse hazard prevention ${ }^{6}$.

After a long history of sustainable farming in Maldives, chemical pesticide use was introduced into farming in the early 90 s which also surged a huge variety of pesticides to the farming industry. Since then, there has been an increase in the suppliers and different varieties in the market, where several pesticides have also been banned from the country due to the toxicity of these products. Lack of knowledge and awareness among the farmers creates an unhealthy cycle of pesticide usage and practices across the country. Furthermore, although the articles' studies describe PPE use in several countries, there is no current overview of PPE use by agricultural pesticide handlers. Despite the fact that some studies explore factors affecting the use of PPE and pesticide safety practices, the informationappears fairly limited and inconsistent. In addition, there are gravely concerning issues related to the patterns of chemical usage across the country such as absence of protective clothing while using pesticides, using the chemicals near to the residential area, the storage and the disposal of these chemicals. Although FAO has issued a manual "Good Agricultural Practices" for the use of chemicals, these rules have not been well implemented in the majority of the islands of the country. The Maldives lacks secondary literatures and relevant studies to properly tackle the critical issue. Therefore, the aim of this study was to determine the chemical pesticide patterns and identify the association between the appropriate use of PPE and other related factors.

\section{Materials and Method}

Study Design: This cross-sectional study used a two-stage random sampling method. A structured questionnaire interview was conducted to collect the data from July to September 2020. 6 islands were selected for the study by using Male' Local Market data and information from the relevant ministries. All fulfilled participants from the inclusion criteria were randomly chosen proportional to the size of the samples to a total of 306 vegetable farming households for the study.

Dependent Variable: Theoutcome wasthe use of Personal Protective Equipment (PPE) while handling, mixing, and spraying chemical pesticides. PPE is defined as any specialized equipment used to minimize the exposure of chemical pesticides to the individuals and the environment ${ }^{6}$. The most important types of PPE refer to the mask for reducing inhalation of chemicals and goggles for protecting the eyes from pesticide hazards. Two of these PPEs or more were used as the cutoff point to determine the outcome of the study. Among 306 samples, only 284 used chemical farming. Those who didnot use any PPEs during the handling of chemical pesticides were coded as 0 . The responses were then created and categorized as a dichotomous variable (Yes/No).

Independent Variables: According to our extensive literature reviews and other relevant studies of the farming industry of the country, a set of self-explanatory variables was selected for the analysis.

Statistical Analysis: All analyseswereperformed using the Stata program version 14.0. The baseline characteristics and other variables were reported as frequency and proportions for categorical data and mean, standard deviation, median, maximum, minimum for continuous data.

To determine the association of using PPE with the independent variables, a simple logistic regression was applied. The independent variables that had a p-value $<0.25$ were processed for the multivariable analysis. The multiple logistic regression was utilized to determine the strength of the association between PPE use and other variables, which adjusted all confounders, and showed adjusted $\mathrm{OR}$, 95\% CI, and P-value. Finally, all variables with p-value less than 0.05 were considered statistically significant.

\section{Results}

Sample Characteristics: The study was conducted in randomly selected 6 islands of the Maldives. Initially, 306 respondents were selected to describe the socioeconomic demographics, farming practices and patterns of pesticide uses. 
The mean age of the farmers was 47.41 years \pm 12.38. $59.48 \%$ were males, $50.33 \%$ received no formal education, and around $63 \%$ had more than or equal 7 people living in the household.

The average monthly household income was MVR $20127.45 \pm 7371$ ( $\$ 1=$ MVR 15.42) and the average monthly household expenditure was MVR 10640.52 \pm 4687(\$1= MVR 15.42).

The results of the number of people living in a household and household expenditure were in line with the national levels, however, the study shows a lower figure in the income value of the households as the mean household expenditure for the atoll is MVR $18000^{7}$.

$55.56 \%$ of the farmers farmed in an area less than 4000sqft indicating the smaller area allocated for farming. The average duration involving in vegetable farming was 11.12 years \pm 6.15 years. $94.12 \%$ of the farmers farmed all year around while $89.87 \%$ of the farmers practices farming in areas far from the household. $24.84 \%$ of the farmers hired labor to spray chemical pesticides, of which $92.11 \%$ were foreigners.

The three main vegetable crops grown by the farmers were Chili, Pumpkin and Cucumber and the three main chemical pesticides used by the farmers were all insecticides, specifically, Avermectin (78.76\%), Imidaclorpid (46.41\%) and Cypermethrin (28.17\%), all insecticides which consistent with a study done in ${ }^{12}$. $78.43 \%$ used chemical pesticides, of which $45.83 \%$ did not used organic pesticides because of inaccessibility to information.

The average number of days per month for spraying chemical pesticides was $3 \pm 1.7$ days and the average amount of chemical pesticides used was $656.49 \pm 443.64 \mathrm{ml}$. Pesticides were mainly purchased from the islands and the $69.01 \%$ of the farmers bought chemical pesticides once every 3 months.

$62.68 \%$ acquired chemical pesticide information from the retailers, creating a huge bias in the use of chemical pesticides. Stakeholders faced several challenges in terms of access on information and to fill the gap in extension. Nearly a quarter $(23.2 \%)$ of the farmers using chemical pesticides had received any form of trainings related to farming.

$82.04 \%$ of the farmers stored chemical pesticides in the farm. 184 farmers have stated to have chemical pesticides without or with an unreadable label, now prohibited under the Pesticide Act of Maldives. 90.49\% of the farmers mixed two or more chemical pesticides and the majority of them burnt or buried chemical containers.

As for the attitude of the farmers towards organic farming, about a quarter $26.41 \%$ were interested in changing their practices.Level of knowledge of the farmers were tested using questions related to chemical pesticides, human health and the environment. 38.73\% of the farmers had a poor knowledge regarding chemical pesticides, while $54.93 \%$ had an average level of knowledge.

The appropriate use of PPE was determined by the use of mask and goggles or any other protective equipment observed in the study. The use of PPE was $33.1 \%$.

Mask was the most used item as a PPE, and boots being the least used item of PPE amongst the vegetable farmers contradicting with a survey in Tanzania ${ }^{7}$ where boots were the most used item and masks being the least.

$48.94 \%$ of the farmers using PPE had a lower PPE rate. The highest use of PPE was $24.47 \%$.

Bivariate Analysis: The bivariate analysis indicated that potentially associated factors with appropriate PPE use ( $p$-value $<0.25$ ) were age, educational attainment, number of people living in the household, farming area, duration involved in farming, hired labor for chemical pesticide spraying, number of days/month the farmers used chemical pesticides, the amount of chemical pesticide used, source of information about chemical pesticides, participation in farming-related training and health literacy. These variables were employed to the multiple variable analysis using multiple logistic regression

Multivariable Analysis: The final model after adjusting for other covariates in the multiple logistic regression demonstrated the appropriate PPE use was significantly associated with thosehad formal education compared to those who did not receive any formal education $(\mathrm{adj} . \mathrm{OR}=3.17,95 \% \mathrm{CI}=1.80-5.57$, $\mathrm{p}$-value $=<0.001$ ). Amount of chemical used by the farmers showed a positive correlation as the higher the number of chemical pesticides was used; the more appropriate PPE has been adopted by the farmers. The farmers who used $\geq 700 \mathrm{ml}$ of pesticides per month were 
2.2 times more likely to use PPE compared to those who used $<700 \mathrm{ml}$ (adj. OR $=2.20,95 \% \mathrm{CI}=1.37-4.43$, $\mathrm{p}$-value $\leq 0.02)$. The farmers hiring foreign labors for the handling, mixing and spraying of chemical pesticides were more likely to use PPE compared to those who never hired anyone for doing such activities (adj. OR=2.46, $95 \% \mathrm{CI}=1.13-4.31$, $\mathrm{p}$-value $=0.02$ ). Source of information about the chemical pesticides was also a significant variable as the farmers who received information from trainings and fellow farmers were proven to use PPE more appropriately than those who mainly acquired the pesticide information from other retailers (adj. OR= $2.31,95 \% \mathrm{CI}=1.33-4.01, \mathrm{p}$-value $=0.003$ ). The odds of appropriate PPE use were 2.97 times higher among farmers who ever participated in any farming-related trainings compared to the farmers who did not receive any forms of trainings (adj. OR $=2.97,95 \% \mathrm{CI}=1.63$ 5.49 , $\mathrm{p}$-value $=<0.001)$ (Table 1).

Table 1: Multivariable analysis of factors associated with the appropriate use of personal protective equipment $(\mathbf{n}=\mathbf{2 8 4})$

\begin{tabular}{|c|c|c|c|c|c|c|}
\hline Variable & Number & \% appropriate PPE & Cr. OR & Adj. OR & $95 \% \mathrm{CI}$ & P-value \\
\hline \multicolumn{6}{|l|}{ Education attainment } & $<0.001$ \\
\hline No formal education & 148 & 22.97 & 1 & 1 & & \\
\hline Received formal education & 136 & 44.12 & 2.65 & 3.17 & $1.80-5.57$ & \\
\hline \multicolumn{6}{|c|}{ Amount of chemical pesticide used per month $(\mathrm{ml})$} & 0.002 \\
\hline$<700$ & 174 & 26.44 & 1 & 1 & & \\
\hline$\geq 700$ & 110 & 43.64 & 2.15 & 2.2 & $1.37-4.43$ & \\
\hline \multicolumn{6}{|c|}{ Do you hire people to spray chemical pesticides? } & 0.020 \\
\hline No & 208 & 25 & 1 & 1 & & \\
\hline Yes & 76 & 36.06 & 1.69 & 2.46 & $1.13-4.31$ & \\
\hline \multicolumn{6}{|c|}{ Where do you mainly get information about chemical pesticides? } & 0.003 \\
\hline From retailers & 178 & 25.28 & 1 & 1 & & \\
\hline Not from retailers & 106 & 46.23 & 2.15 & 2.31 & $1.33-4.01$ & \\
\hline \multicolumn{6}{|c|}{ Did you participate in any farming-related trainings? } & $<0.001$ \\
\hline No & 71 & 26.76 & 1 & 1 & & \\
\hline Yes & 213 & 52.11 & 2.98 & 2.97 & $1.63-5.49$ & \\
\hline
\end{tabular}

\section{Discussion and Conclusion}

Discussion: Ourcurrent study identified and discussedthe pattern of pesticide used and factors associated with the appropriate use of personal protective equipment among vegetable farmers in the Maldives. The results showed that approximately $90 \%$ of the vegetable farmers used chemical pesticides. Pesticide usage in vegetable production has been increasing around the world and the pesticide use reflects the situation in underdeveloped and developing countries ${ }^{11,13,15}$.

The socio-economic demographics of the study determined that approximately $70 \%$ of the vegetable farmers were above 40 years old. The engagement of youth in farming was low. However, this contradicts with the study ${ }^{11}$ whereas more than $50 \%$ of the farmers in the study were younger than 40 years old. The main socio-economic factor that correlated with the use of PPE was the education attainment of the farmer. As the farmers have been involved in the farming sectors for a longer period of time, the older population had basic or no formal education. With a very few exceptions, the only available educational facilities before the 1970s were 'edhuruge' [literally teacher's house] run by individuals or communities expanded during the study 115-year period into a full-fledged public-funded education system by $2005^{16}$ indicating that two-third of the farmers received no formal education.

The income and expenditure of the farming in the household was not significant in the study, mainly due 
to farming being a secondary economic activity in the households and did not reflect the total income and expenditure of the household.

The increase in the amount of the use of pesticides and the use of PPE showed a significant relationship. This may be because farmers are more cautious that they encounter higher risks and adverse effects with a greater dose of chemical pesticides. The farmers were more inclined to use PPE with more chemical pesticide use as most farmers in the study were well aware of the common knowledge of pesticides and the harm to human and health and environment ${ }^{13}$.

Only one-fourth of the farmers in the study had received any farming trainings which was consistent with other studies ${ }^{12}$. However, trainings from governments and extension services and training programs are crucial factors in promoting the use of PPE and pesticide safety practices ${ }^{11}$. This study confirmed that farmers who acquired their information fromretailers were less likely to use PPE than the farmers who got information from other sources such as other fellow farmers and trainings. Retailers may prefer to sell their products rather than allow the farmers to take their own decisions ${ }^{13}$.Training the retailers about the correct use of chemical pesticides and protective equipment is absolutely vital as they are the primary source of information for the farmers ${ }^{6}$.

Of the 306 participants of the study, 30\% of the farmers have been farming for over 15 years. However, approximately $25 \%$ of the farmers had received any types of trainings over the years. The use of PPE showed a significant relationship with the trainings with $\mathrm{p}<0.001$.

As the proper use of PPE reduced the implications on the health of the farmers ${ }^{14}$. Therefore, the use of PPE and the adoption of other safely protective measures and attitudes during preparation and application of pesticides are extremely crucial to mitigate occupational exposure to pesticides ${ }^{15}$. Farmer trainings can be a key tool to increase the use of PPE and to adopt Good Agriculture Practices in vegetable farming. Trainings are associated with increased levels of farmers' knowledge of pesticides, and was accompanied by elevated safety behavior, and thus was connected by lower occupational exposure to pesticides ${ }^{17}$.

Limitation: The present study covered major areas of vegetable farming from 6 islands and selected an enough size representative to the total population of the country. However, the in-depth study on the issues could help getting detailed to improve the use of PPE.

\section{Conclusion}

Almost all of the vegetable farmers used chemical pesticides, however, nearly a quarter of respondents had used the PPE. The statistically significant factors associated with the appropriate use of PPE were educational attainment, quantity of chemical pesticides used, hired labor for spraying, main source of chemical pesticide information, and participation in any trainings related with farming.

The major factors determining the appropriate use of these PPE was proven to be strongly related to the information and awareness of the farmer related with farming practices, hence, the government, organizations, and relevant stakeholders need to conduct specific training programs to raise the awareness of both the farmers and the public. Moreover, a cross sectional study of chemical pesticide use and the effects on health and the environment would be helpful for the farmers to understand a better picture of the effects of chemical pesticide exposure.

Ethical Considerations: This study received an approval from Khon Kaen University, Ethics Committee for Human Research. After the clear clarification of the purpose of the study and the method of conducting the study, a written consent was taken from all the participants.

Acknowledgement: The authors are truly grateful and thankful to the Thailand International Cooperation Agency for funding this independent Study and the KhonKaen University for the technical support.

Conflict of Interest: No conflicts of interestto declare.

Source of Funding: Thailand International Cooperation Agency (TICA).

\section{References}

1. Food and Agriculture Organization. International Code of Conduct on the Distribution and Use of Pesticides. Rome: FAO; 2003.

2. Macharia, I., 2015. Pesticides and Health in Vegetable Production in Kenya. BioMed Research International, 2015, p.20.

3. Aktar W, Sengupta D, Chowdhury A. Impact of pesticides use in agriculture: their benefits and 
hazards. Interdisciplinary Toxicology. 2009;2(1):112.

4. Jeyaratnam J. Acute pesticide poisoning: a major global health problem. World Health Stat Q; 1990 p. 139-144.

5. PAN Germany. Pesticides and health hazards: Facts and figures. Germany; 2012.

6. Food and Agriculture Organization. Advancement of pesticide regulatory management in Asia. Bangkok: FAO; 2013.

7. National Bureau of Statistics. Household Income and Expenditure Survey. Male': National Bureau of Statistics; 2016.

8. Jallow M, Awadh D, Albaho M, Devi V, Thomas B. Pesticide Knowledge and Safety Practices among Farm Workers in Kuwait: Results of a Survey. International Journal of Environmental Research and Public Health. 2017;14(4):5-15.

9. Jeyaratnam J, Alwis Seneviratne R, copplestone J. Survey of Pesticide Poisoning in Sri Lanka. 60:615619.

10. Schreinemachers P, Afari-Sefa V, Heng C, Dung P, Praneetvatakul S, Srinivasan R. Safe and sustainable crop protection in Southeast Asia: Status, challenges and policy options. Environmental Science \& Policy. 2015;54:357-366.

11. Food and Agriculture Organization. International Code of Conduct on the Distribution and Use of Pesticides. Rome: FAO; 2003.
12. Bhandari G, Atreya K, Yang X, Fan L, Geissen $\mathrm{V}$. Factors affecting pesticide safety behaviour: The perceptions of Nepalese farmers and retailers. Science of The Total Environment. 2018;631632:1560-1571.

13. Lekei E, Ngowi A, London L. Farmers' knowledge, practices and injuries associated with pesticide exposure in rural farming villages in Tanzania. BMC Public Health. 2014;14(1).

14. 15. Ali M, Kabir M, Haque S, Qin X, Nasrin S, Landis D et al. Farmer's behavior in pesticide use: Insights study from smallholder and intensive agricultural farms in Bangladesh. Science of The Total Environment. 2020;747.

15. Sapbamrer R, Thammachai A. Factors affecting use of personal protective equipment and pesticide safety practices: A systematic review. Environmental Research. 2020;185:109444.

16. Macharia I. Pesticides and Health in Vegetable Production in Kenya. BioMed Research International. 2015;2015:1-10.

17. Ali A. Policy processes in the evolution of education in the Maldives: 1900 - 2015. 2018;.

18. Damalas C, Koutroubas S. Farmers' Training on Pesticide Use Is Associated with Elevated Safety Behavior. Toxics. 2017;5(3):19. 